\title{
DỨcin
}

Technological University Dublin ARROW@TU Dublin

2015-11-01

\section{Raman spectroscopy for screening and diagnosis of cervical cancer}

\author{
Fiona Lyng \\ Technological University Dublin, fiona.lyng@tudublin.ie \\ Damien Traynor \\ Technological University Dublin \\ Ines RM Ramos \\ Technological University Dublin
}

See next page for additional authors

Follow this and additional works at: https://arrow.tudublin.ie/biophonart

Part of the Biochemistry, Biophysics, and Structural Biology Commons, and the Physics Commons

\section{Recommended Citation}

Lyng, F. et al. (2015) Raman spectroscopy for screening and diagnosis of cervical cancer", Analytical and Bioanalytical Chemistry, 407, 8279-8289 (2015). doi:10.1007/s00216-015-8946-1

This Article is brought to you for free and open access by the DIT Biophotonics and Imaging at ARROW@TU Dublin. It has been accepted for inclusion in Articles by an authorized administrator of ARROW@TU Dublin. For more information, please contact arrow.admin@tudublin.ie, aisling.coyne@tudublin.ie, gerard.connolly@tudublin.ie.

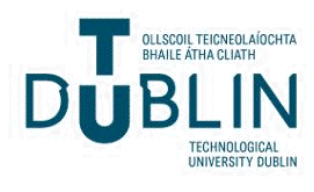




\section{Authors}

Fiona Lyng, Damien Traynor, Ines RM Ramos, Franck Bonnier, and Hugh Byrne

This article is available at ARROW@TU Dublin: https://arrow.tudublin.ie/biophonart/24 


\section{Raman spectroscopy for screening and diagnosis of cervical cancer}

Fiona M. Lyng ${ }^{\mathrm{a}, \mathrm{b}}$, Damien Traynor ${ }^{\mathrm{a}, \mathrm{b}}$, Inês R. M. Ramos ${ }^{\mathrm{a}, \mathrm{b}}$, Franck Bonnier ${ }^{\mathrm{c}, 1}$ and Hugh J. Byrne

${ }^{a}$ DIT Centre for Radiation and Environmental Science, FOCAS Research Institute, Dublin Institute of Technology,

Kevin St, Dublin 8, Ireland

${ }^{\mathrm{b}}$ School of Physics, Dublin Institute of Technology, Kevin St, Dublin 8, Ireland

${ }^{c}$ FOCAS Research Institute, Dublin Institute of Technology, Kevin St, Dublin 8, Ireland

*Corresponding author:

Prof. Fiona M. Lyng

DIT Centre for Radiation and Environmental Science,

FOCAS Research Institute

Dublin Institute of Technology

Kevin St

Dublin 8

Ireland

t: +35314027972

f: +35314027904

e : fiona.lyng@dit.ie

\footnotetext{
${ }^{1}$ Present address: Université François-Rabelais de Tours, Faculty of Pharmacy, EA 6295 Nanomédicaments et Nanosondes, 31 avenue Monge, 37200 Tours, France
} 


\begin{abstract}
Cervical cancer is the fourth most common cancer in women worldwide and mainly affects younger women. The mortality associated with cervical cancer can be reduced if this disease is detected at the pre-cancer stage. Current gold standard methods include cytopathology, HPV testing and histopathology but these methods are limited in terms of subjectivity, cost and time. There is an unmet clinical need for new methods to aid clinicians in the early detection of cervical pre-cancer. These methods should be objective, rapid and require minimal sample preparation. Raman spectroscopy is a vibrational spectroscopic technique by which incident radiation is used to induce vibrations in the molecules of a sample and the scattered radiation may be used to characterise the sample in a rapid and nondestructive manner. Raman spectroscopy is sensitive to subtle biochemical changes occurring at the molecular level allowing spectral variations corresponding to disease onset to be detected. Over the past 15 years, there have been numerous reports showing the potential of Raman spectroscopy together with multivariate statistical analysis for the detection of a variety of cancers. This paper discusses the recent advances and issues for cervical cancer screening and diagnosis and offers some perspectives for the future.
\end{abstract}

\title{
Keywords
}

Raman spectroscopy, cervical cancer, cervical intraepithelial neoplasia (CIN), low grade squamous intraepithelial lesion (LSIL), high grade squamous intraepithelial lesion (HSIL), cytopathology, histopathology, human papilloma virus (HPV) 


\section{Cervical cancer}

Cervical cancer is the fourth most common cancer in women worldwide, accounting for an estimated 528,000 new cases and 266,000 deaths in 2012 [1]. The mortality associated with cervical cancer can be reduced if this disease is detected at the early stages of development or at the pre-malignant stage (cervical intraepithelial neoplasia, CIN). Unlike most other types of cancer, cervical cancer affects mainly younger women, with about $60 \%$ of cases occurring in women under 50 years of age. Persistent infection with high risk human papillomavirus (HPV) (e.g., HPV types 16,18 ) is accepted as the major cause for the development of cervical pre-cancer and cancer [2]. Other risk factors include smoking, immunosuppression, long term use of oral contraceptives and socioeconomic status [3]. Cervical cancer begins in the basal layer of cells lining the cervix when the normal cells slowly change into precancer cells that have the potential to turn into cancer. The gradual progression of cervical cancer can allow the detection of dysplastic changes before invasive cancer develops, through cervical cancer screening programmes. These screening programmes are common in developed countries, greatly reducing the mortality rates due to cervical cancer, but are not yet implemented in developing countries due to lack of infrastructure and funding.

\section{Cervical cancer screening and diagnosis}

\subsection{The Pap test}

The Pap test, also called the Pap smear, cervical smear or smear test, is a screening method invented independently by Georgios Papanicolau and Aurel Babeş, but named after Papanicolau. It was introduced in the mid 1940s and currently it is the most common screening method for cervical neoplasia and its precursor lesions [4].

The smear is collected by scraping the internal wall of the cervix with a cervical brush to obtain representative material from the transformation zone where the stratified squamous epithelium of the ectocervix turns into the columnar mucus secreting epithelium of the endocervix. The cells are then transferred onto a microscope slide by either the conventional method, in which the cells are spread along the slide immediately after collection and fixed with a spray fixative, or by liquid based cytology (LBC), in which the cells are transferred immediately after collection into a vial with a fixative solution and subsequently processed to remove debris and transferred to a slide (ThinPrep® (Hologic) or SurePath® (BD)).

Once on a slide, the cells are Pap stained and evaluated under the microscope by a highly trained cytotechnologist or a pathologist according to the Bethesda system [5]. 
Cervical cytology is normally graded as negative (negative for intraepithelial lesion or malignancy [NILM]), low grade squamous intraepithelial lesion [LSIL] and high grade squamous intraepithelial lesion [HSIL]. LSIL may regress but HSIL is unlikely to do so and may progress to invasive disease. Current guidelines are that LSIL cases are re-tested after 6 months and HSIL cases are referred to colposcopy [6].

A normal Pap stained cervical smear, such as that shown in figure 1, typically shows cells from the surface of the epithelium; intermediate cells, which are large polygonal cells with a round to oval nucleus and a blue stained cytoplasm, and superficial cells, which are large polygonal cells with a small condensed nucleus and a pink to orange stained cytoplasm. Parabasal cells, which are small round or oval cells with the nucleus occupying half of the cell and a dense blue stained cytoplasm, can also be found, but these are more prominent in smears from postmenopausal women. Metaplastic cells, endocervical cells and endometrial cells can also all be present in a normal smear. The most common non-epithelial cells present in the normal smear are white blood cells, including polymorphs (neutrophils) or macrophages (histiocytes), which can increase in number due to infection and inflammation.

The advantages of the Pap test are that it is non-invasive, inexpensive and widely accepted. However, although it can have high specificity of up to $95-98 \%$, sensitivity rates have been shown to vary from 74 to $96 \%$ due to sampling, technical and/or interobserver errors mainly associated with the subjectivity of the cytological screening [7].

Semi-automated screening systems consist of an automated microscope coupled to a workstation running image processing algorithms. Slides are scanned initially and cells of interest are separated from the background of inflammatory cells, cellular debris or overlapping cell clusters. Image segmentation algorithms perform a separation of the nuclei from the cytoplasm of the cells allowing the calculation of nuclear size, nucleus to cytoplasm ratio or even definition of the texture of the observed object. None of the currently available systems, however, FocalPoint ${ }^{\mathrm{TM}}$ GS Imaging system (BD) or the ThinPrep ${ }^{\mathrm{TM}}$ Imaging system (Hologic), provides fully automated screening without human intervention at some stage. The final decision still lies with the cytologist, resulting in the same subjectivity problem as in manual screening. The MAVARIC trial [7] showed no improvement in sensitivity or specificity of automated screening when compared to manual screening or in cost-effectiveness despite a $60 \%-80 \%$ increase in productivity for automated screening. 


\subsection{HPV testing}

HPV testing trials have recently been conducted in order to evaluate their effectiveness for primary and secondary screening as well as for proof-of-cure for safe and cost-effective lengthening of the cervical screening interval due to high negative predictive values [8]. Many studies have shown that HPV testing has higher sensitivity ( $>95 \%)$ but lower specificity $(\sim 84 \%)$ than cytology $[9,10]$. HPV DNA tests, such as Hybrid Capture 2 (Qiagen), Cervista HPV HR and Cervista HPV 16/18 (Hologic) and cobas HPV (Roche) assays, identify high-risk HPV oncogene expression, while HPV E6/E7 mRNA based assays, such as APTIMA HPV assay (Gen Probe), identify the messenger RNA of two HPV viral oncogenes, E6 and E7. However, these tests are expensive, time-consuming and provide no information on cervical cytopathology. Over the last decade, prophylactic HPV vaccines have been developed, but, despite the introduction of these vaccines, there is still a need for regular cervical screening, as the vaccines do not protect against all oncogenic HPV types. Additionally, some women may not benefit from the vaccines if there is a pre-existing HPV infection or they do not receive the complete number of doses. After vaccination, women must still have routine Pap tests which can detect abnormal cervical growth regardless of what HPV type causes it to develop [11].

\subsection{Histopathology}

An abnormal Pap smear is followed by colposcopy, biopsy and histopathology. Microscopic evaluation by a pathologist of a stained tissue section obtained from a biopsy is currently regarded as the "gold standard" in cancer diagnostics and is called pathologic histology or histopathology.

After collection during colposcopy, the tissue is fixed and processed into a paraffin wax block. Tissue sections, usually between 2 - $7 \mu \mathrm{m}$, are cut on a microtome and transferred to a slide for staining with Haematoxylin \& Eosin (H\&E). The histological slide is then ready for examination under a light microscope by a trained pathologist. Figure 2 shows a H\&E stained normal cervical tissue section showing stromal, basal / parabasal and intermediate / superficial layers. Based on histopathological characteristics of the tissue, grading assesses the degree of malignancy or aggressiveness of the abnormal cells by comparing various parameters such as cellular anaplasia, differentiation and mitotic activity with counterparts in normal cells and tissue. However, the grading characteristics can be quite subjective and pre-malignancy may not be visually perceptible at all. The sensitivity and specificity of colposcopy guided biopsy has been shown to be $75-90 \%$ and $97-99 \%$ respectively [12], but the subjective interpretation of histologic classification is the main issue leading to poor inter-observer agreement [13 - 15]. 
Current gold standard methods for detection of cervical cancer and pre-cancer are therefore limited and there is an unmet clinical need for new objective screening or diagnostic tests.

\section{Raman spectroscopy}

Vibrational spectroscopy analyses vibrations within a molecule and the spectrum of vibrational energies or

frequencies (in wavenumbers, $\mathrm{cm}^{-1}$ ) can be used to characterise a molecular structure. Every molecule has a unique spectrum which allows identification of the molecular compound and its abundance in a sample [16]. The exact energy required to excite a molecular vibration depends on the masses of the atoms involved in the vibration and the strength of the chemical bonds between these atoms and may be influenced by molecular structure, molecular interactions and the chemical microenvironment of the molecule.

Raman spectroscopy is an optical method based on inelastic light scattering. The sample is illuminated by monochromatic laser light and interactions between the incident photons and molecules in the sample result in scattering of the light. The coupling of the light generates vibrations within the material, which are again characteristic of the chemical structure, and the energy of the scattered light is reduced by an amount equal to the energy of the vibrational energy. Thus, the positions, relative intensities and shapes of the bands in a Raman spectrum carry detailed information about the molecular composition of the sample.

Raman spectra of biomedical samples such as cells and tissues are a superposition of all the contributions from each individual biochemical component such as DNA, RNA, proteins, lipids and carbohydrates. Thus, Raman spectroscopy can provide a molecular diagnosis by providing a "biochemical fingerprint" of the complete genome, proteome and metabolome of the cell or tissue [17]. This can be provided in a rapid, label free, non-destructive manner, allowing additional analyses to be performed subsequently, such as staining, immunocytochemistry etc. In recent years, Raman spectroscopy has been used in the detection of a variety of cancers, including breast, prostate, oesophageal, colon, lung, oral and cervical cancer, and excellent sensitivity and specificity values have been reported [18-20].

A typical Raman spectrum of cervical cells is shown in Figure 3, and a list of tentative spectral assignments is provided in Table 1 [21]. The Raman spectrum was acquired using a HORIBA Jobin Yvon XploRA ${ }^{\mathrm{TM}}$ system (Villeneuve d'Ascq, France), which incorporates an Olympus microscope BX41 equipped with a x100 objective (MPlanN, Olympus, NA = 0.9) and a $532 \mathrm{~nm}$ diode laser source. The power of the laser was set at $50 \%$, resulting in $\sim 8 \mathrm{~mW}$ at the objective. The confocal hole coupled to a slit of aperture $100 \mu \mathrm{m}$, was set at $100 \mu \mathrm{m}$ and a 1200 lines/mm grating was used. The system was pre-calibrated to the $520.7 \mathrm{~cm}^{-1}$ spectral line of silicon. The 
backscattered light was measured using an air-cooled CCD detector (Andor, 1024 x 256 pixels). Three spectra were recorded from the cervical epithelial cell nucleus, each corresponding to the average of 3 accumulations of 10 seconds. Spectral pre-processing was performed using Matlab software (Mathworks) including smoothing (SavitzkyGolay, $\mathrm{k}=5 ; \mathrm{w}=13$ ), baseline correction (rubber band) and vector normalisation. The spectrum can be divided into two regions, the fingerprint region, from $400-1800 \mathrm{~cm}^{-1}$, and the high wavenumber region, from $2500-3500 \mathrm{~cm}^{-1}$. The high wavenumber region is dominated by $\mathrm{C}-\mathrm{H}, \mathrm{N}-\mathrm{H}, \mathrm{O}-\mathrm{H}$ vibrations and can provide significant chemically specific information, particularly on lipidic and protein structures. The fingerprint region similarly contains features which can be associated with specific chemical moieties (e.g. $\mathrm{C}=\mathrm{C}, \mathrm{C}=\mathrm{O}$ ) but also contains features associated with combinations of modes and more extensive macromolecular vibrations such as skeletal vibrations. As it is considerably richer in information, it is often favoured for (multivariate) chemical analysis.

\subsection{Raman spectroscopy for cytopathology}

As shown in figure 1, a typical normal cervical smear contains epithelial cells, such as superficial cells, intermediate cells, parabasal cells, as well as metaplastic cells, endocervical cells and endometrial cells, and non-epithelial cells, such as white blood cells. Figure 4 shows an unstained cervical smear sample and the same sample after Pap staining with the cells of interest indicated by arrows. Mean Raman spectra recorded from the unstained sample from superficial cells, intermediate cells, parabasal cells and white blood cells are also shown. Raman spectra were acquired as previously described for Figure 3. The spectra show considerable similarity as they are all measured from the cell nucleus but some qualitative differences can also be found. The white blood cells show increased contributions from nucleic acid bases around $800 \mathrm{~cm}^{-1}$ and $1580 \mathrm{~cm}^{-1}$. Parabasal cells show increased contributions from Amide III and phosphate stretching at $1240 \mathrm{~cm}^{-1}$ while superficial cells differ from intermediate cells mainly due to increased contributions from guanine and $\mathrm{C}-\mathrm{H}$ deformation in proteins and carbohydrates at 1340 $\mathrm{cm}^{-1}$.

Interestingly, the Raman spectra in figure 4 were recorded directly from Thinprep slides prepared according to current cytopathology laboratory standard procedures apart from the Pap stain. The $\mathrm{x}$, y co-ordinates of each recorded cell were saved and, after Raman recording at $532 \mathrm{~nm}$, the slides were Pap stained and each cell was revisited to verify whether it was a superficial, intermediate, parabasal or white blood cell. Spectroscopic substrates, such as calcium fluoride, are commonly used for research purposes and although they reduce the presence of confounding contributions of the substrate [22-24], they are considerably more expensive and thus not really a viable choice for population screening applications such as cervical cancer screening. Although $785 \mathrm{~nm}$ is commonly used 
for biological applications of Raman spectroscopy, glass shows a strong background at this wavelength so to use glass as a substrate for Raman spectroscopy, spectra must be recorded using shorter wavelengths such as $532 \mathrm{~nm}$.

Initial vibrational spectroscopic studies (InfraRed spectroscopy) on cervical cytopathology performed in the early 1990's recorded spectra from cell pellets rather than from individual cells [25-27] and a number of confounding factors such as the presence of polymorphs, endocervical columnar cells, metaplastic cells, cervical mucus, blood and debris were subsequently identified [28-33]. There have been relatively few studies using Raman spectroscopy for cervical cytopathology, most likely because of issues with confounding factors.

A study by Rubina et al. [34] used Raman spectroscopy to distinguish between normal and cervical cancer cytology samples. As the spectra of cervical cancer samples were dominated by blood features, cytology samples were treated with red blood cell lysis buffer prior to Raman acquisition. However, the use of cell pellets rather than recording Raman spectra from individual cells probably resulted in the relatively low classification accuracy of $80 \%$ due to sample heterogeneity.

A recent study from our group [35] addressed many of the issues involved in recording Raman spectra from ThinPrep cervical cytology samples. A new method based on pre-treatment of the slides with hydrogen peroxide to clear blood residue contamination before Raman recording was shown to minimise variability within the data sets. This resulted in the collection of highly reproducible data with clear discrimination between negative cytology and CIN cytology. Importantly, all data was recorded on glass ThinPrep slides, commonly used in cytopathology laboratories.

\subsection{Raman spectroscopy for detection of HPV infection}

HPV infection is accepted as one of the major risk factors associated with cervical cancer and detection of HPV infection is being introduced as a routine screening methodolology. Incorporation of the virus into the cell induces significant changes in the biochemistry which should also be identifiable using Raman spectroscopy.

Raman microspectroscopy has been used to distinguish between primary human keratinocytes (PHK), PHK cells expressing the E7 gene of HPV16 (PHK E7) and cervical cancer cells expressing HPV16 (CaSki). The mean Raman spectra showed variations in DNA and protein, consistent with HPV gene expression and neoplasia. Using principal 
component analysis (PCA), Raman spectroscopy was shown to discriminate between PHK and CaSki cells with a sensitivity of $93 \%$ and a specificity of $93 \%$ and between PHK and PHK E7 cells with a sensitivity of $93 \%$ and a specificity of $80 \%$ [36].

Ostrowska et al. [37] used both infrared absorption and Raman spectroscopy to study a range of cervical cancer cell lines. HPV negative (C33a) and low HPV copy number ( $\mathrm{SiHa}$ with 1-2 copies) cell lines were shown to be biochemically similar but significantly different from mid (HeLa) and high (CaSki) HPV copy number cervical cancer cell lines. The main variations were observed for protein, nucleic acid and lipid and were confirmed by both mean spectra and PCA analysis. Notably, the application of multivariate Partial Least Squares Regression analysis, with HPV copy number as target, demonstrated that the dataset can be used to evaluate the degree of HPV infection, based on the spectral profile of the cells.

A study by Vargis et al. [38] used both cell lines and cytology samples to investigate the potential of Raman microspectroscopy to detect the presence of HPV. Classification accuracies of 89-93\% were achieved for discrimination between a HPV negative normal human keratinocyte cell line (NHEK), a HPV negative cervical cancer cell line (C33a) and HPV positive cervical cancer cell lines (HeLa and SiHa). A classification accuracy of 98.5\% was achieved for discrimination between HPV-positive and HPV-negative cytology samples.

\subsection{Raman spectroscopy for histopathology}

As shown in figure 2, a typical normal cervical tissue section contains different cell layers such as stromal, basal / parabasal and intermediate / superficial layers. Figure 5 shows parallel H\&E stained and unstained cervical tissue sections and a four cluster Raman spectral map showing three distinct layers. The Raman map was recorded using a HORIBA Jobin Yvon HR 800 (Villeneuve d'Ascq, France) Raman microscope equipped with a x100 objective $($ MPlanN, Olympus, NA $=0.9)$ and a $785 \mathrm{~nm}$ laser source. Raman scattering was collected through a $100 \mu \mathrm{m}$ confocal hole onto a Synapse air-cooled CCD detector for the range of 400-1800 $\mathrm{cm}^{-1}$ using a 300 lines/mm diffraction grating, yielding a dispersion of $\sim 1.5 \mathrm{~cm}^{-1}$ per CCD pixel. The instrument was calibrated using the 520.7 $\mathrm{cm}^{-1}$ peak of silicon. Raman spectral mapping was performed using 2 x 15 seconds acquisitions with a step size of $18 \mu \mathrm{m}$. Spectral pre-processing was performed using Matlab software (Mathworks) including smoothing (SavitzkyGolay, $\mathrm{k}=5$; w=13), baseline correction (rubber band) and vector normalisation. K Means Cluster Analysis was used to analyse the spectral data set from the Raman map. The blue cluster represents the stroma, the red cluster the basal 
/ parabasal layer, the green cluster the intermediate / superficial layer and the black cluster the substrate. Mean Raman spectra representing the different clusters are also shown in figure 5. The most distinctive Raman bands in the blue spectrum can be assigned to collagen $\left(853 \mathrm{~cm}^{-1}, 921 \mathrm{~cm}^{-1}, 938 \mathrm{~cm}^{-1}\right.$ and $\left.1245 \mathrm{~cm}^{-1}\right)$ a major component of the connective tissue layer or stroma. The red spectrum shows distinctive bands due to DNA bases, adenine $\left(722 \mathrm{~cm}^{-1}\right)$, thymine $\left(755 \mathrm{~cm}^{-1}\right)$ and cytosine $\left(782 \mathrm{~cm}^{-1}\right)$, and the green spectrum shows bands at $480 \mathrm{~cm}^{-1}, 849 \mathrm{~cm}^{-1}$ and $938 \mathrm{~cm}^{-1}$ indicating the accumulation of glycogen in the intermediate / superficial layer.

Krishna et al. studied formalin fixed cervical tissues using both Raman and FTIR spectroscopy. Normal and malignant tissues could be distinguished with differences in protein, lipids and nucleic acid peaks and stronger Amide III assignments, suggesting disordered, helical secondary protein structure, in malignant conditions [39]. Formalin fixed paraffin preserved (FFPP) cervical tissue sections were also investigated by Lyng et al. [40]. The underlying biochemical changes associated with cervical precancer and cancer were shown to be due to a reduction in glycogen and an increase in nucleic acids. The loss of differentiation, together with increased proliferation, in precancer results in reduced levels of glycogen, as normal cervical cells accumulate glycogen as they mature. A Raman mapping study using frozen tissue sections showed that Raman spectroscopy could distinguish normal cervical tissue from invasive cervical cancer tissue based mainly on collagen bands and $\mathrm{CH}$ stretching bands [41].Tan et al. [42] used Raman spectral mapping and hierarchical cluster analysis (HCA) to differentiate between normal squamous epithelium and CIN2 in FFPP tissue sections and it was shown that the Raman spectra associated with the CIN2 lesion clustered predominantly with those of the basal epithelial cells of the normal squamous epithelium, suggesting that the cells of these regions share common biochemical profiles. Spectral features responsible for their differentiation were associated with the amide I and amide III bands.

More recently, FFPP tissue sections from cervical biopsies classified as NILM, LSIL or HSIL were analysed by Raman spectral mapping [43]. Together with K-means cluster analysis (KMCA), Raman mapping was able to differentiate the NILM cervical tissue into three layers including stroma, basal/parabasal and superficial layers, characterised by spectral features of collagen, DNA bases and glycogen respectively. In the LSIL and HSIL samples, KMCA clustered regions of the superficial layer with the basal layer. Using PCA, biochemical changes associated with disease were also observed in normal areas of the abnormal samples, where morphological changes were not apparent, providing a clear indication of the potential of Raman spectroscopy to identify biochemical changes associated with the initial stages of the disease, rather than just the morphological changes associated with later stage disease and current clinical diagnosis. 


\subsection{Raman spectroscopy for in vivo applications}

Mahadevan-Jansen et al [44, 45] first showed the potential of Raman spectroscopy for in vivo detection of cervical cancer and pre-cancer and developed a fibre optic probe for in vivo measurements. Increases in phospholipids and DNA, 1330, 1454 and $1650 \mathrm{~cm}^{-1}$, were associated with progression to high-grade dysplasia [44, 45]. Improvements in the overall classification accuracy of Raman spectroscopy from $88 \%$ to $94 \%$ were achieved by including information on menopausal status and menstrual cycle [46]. Similarly, consideration of previous disease history and proximity to dysplastic lesions was found to result in disease classification accuracy of 97\% [47]. Further studies investigated the influence of race, ethnicity, body mass index, parity and socioeconomic status on Raman spectra from patients with a normal cervix and concluded that only body mass index and parity resulted in significant variations of spectral profiles [48]. Their influence on dysplasia and cancer has not been assessed, however. The potential of high wavenumber $\left(2800-3700 \mathrm{~cm}^{-1}\right)$ Raman spectroscopy for in vivo detection of cervical pre-cancer has been explored by Huang and co-workers $[49,50]$. Significant differences in Raman bands of lipids at 2850 and $2885 \mathrm{~cm}^{-1}$, proteins at $2940 \mathrm{~cm}^{-1}$ and the broad Raman band of water at $3400 \mathrm{~cm}^{-1}$ were observed in normal and dysplastic cervical tissue, with a sensitivity of $93.5 \%$ and specificity of $97.8 \%$ achieved for identification of dysplasia [49]. Simultaneous fingerprint and high wavenumber Raman spectroscopy has been shown to outperform fingerprint or high wavenumber Raman spectroscopy alone, resulting in a sensitivity of $85.0 \%$, specificity of $81.7 \%$, and overall diagnostic accuracy of $82.6 \%$. Raman spectral differences between normal and dysplastic cervical tissue were observed at $854,937,1001,1095,1253,1313,1445,1654,2946$, and $3400 \mathrm{~cm}^{-1}$, mainly related to proteins, lipids, glycogen, nucleic acids and water content in tissue [50].

\section{Future perspectives}

The potential of Raman spectroscopy as a truly label free, objective, automatable diagnostic technique has been well demonstrated through numerous research studies of numerous pathologies, both in vivo and ex vivo. Disease diagnostics have long relied on visual differences in tissue appearance, aided in modern histopathology and cytology by optical stains and microscopic technologies. However, such approaches, based on changes in tissue and cell morphology, often show the later stages of disease development, rather than the underlying biochemical changes associated with disease onset or aetiology. Raman spectroscopy provides a signature, or fingerprint of the biological sample, based on the biochemical constituents, and subtle changes to the composition associated with disease or external insult can be identified with high sensitivity with the aid of multivariate statistical analysis. As an optical 
technology, it can be applied microscopically or endoscopically, for ex vivo or in vivo applications, the former including cytopathology or histopathology. Signatures of viral infection can also be clearly identified indicating that the technique could ultimately compete with costly viral screening programmes, notably with the same instrumentation and an integrated screening protocol.

Table 2 lists the advantages and disadvantages of the current screening/diagnostic methods and Raman spectroscopy for cervical cancer. In cytology, the Pap smear test, and in histology, histochemical staining are well established and in essence considered "gold standards". Any new disruptive technology such as spectropathology has an obvious relative disadvantage in that translation will require not only acceptance by the clinical community, but large scale and costly clinical trials. Ultimately, although both current cytological and histological methods require ex vivo samples and are thus to some degree invasive, Raman based spectropathology could be performed in vivo in a completely non invasive fashion. The principle advantage of spectroscopic based techniques is that, once established, the technique is completely objective, based on disease and/or disease aetiology related changes in biochemical signatures, rather than relying on expert interpretation of morphological changes. This should minimise the risk of misdiagnosis due to variations in subjective human interpretation. Rapid analysis should also result in rapid turn around to minimize patient anxiety. To date, much of the proof of concept research has been carried out on high specification, laboratory apparatus, requiring expert users. However, given the increasing availability of lower specification and cost, user friendly Raman instruments, this technology could readily translate to clinical laboratories. Although the readout is a Raman spectrum, using pre-defined classification algorithms, a non-specialist operator could receive an output such as a yes, no, or maybe (or Red, Orange Green) indicator for the presence of cancer or pre-cancer.

However, despite the obvious potential, to date vibrational spectroscopic techniques have seen limited if any translation into the clinical environment. A critical assessment of the challenges facing the translation of spectroscopic methods to the clinical arena has recently been presented [51]. "Spectropathology for the Next Generation: Quo Vadis?" summarises the discussion sessions of the SPEC 2014 conference, the $8^{\text {th }}$ in the series of bi-ennial flagship conferences in the field, which were led by members of the International Advisory Board. Although the potential of the techniques has been well demonstrated in the research environment, and many of the technical challenges associated with sample presentation, data acquisition, processing and analysis have been addressed, it is clear that the lack of studies of the scale of clinical relevance is an obstacle to their credibility and uptake. Widespread engagement of the medical community and commitment from instrument manufacturers as well 
as the resources required for large scale clinical trials may depend on the availability of such large scale studies. In this context, the identification of strategic, achievable target applications is recommended.

Due to the high throughput of established screening programmes, cervical cytopathology is potentially such a strategic target application. A key consideration is how the spectroscopic technique could fit into the current workflow. Notably, the Pap smear protocol introduces cytological stains which can interfere with the Raman acquisition, introducing substantial fluorescence background and/or photodegradation, depending on the wavelength employed. With automated spectral acquisition, however, the implementation could be similar to the Thinprep Imager (Hologic) or the Focal Point GS Imaging system (BD), which use image processing algorithms to automatically review liquid based cytology Thinprep and SurePath slides. Raman spectroscopy is reagent free, so costs should be favourable when compared to the imaging systems or to manual scoring where personnel costs could be reduced. A recent study by our group [35] has shown that glass ThinPrep slides can be used for Raman spectral recording in place of spectroscopic substrates, such as calcium fluoride substrates. These substrates reduce the presence of confounding contributions of the substrate but they are considerably more expensive than the glass slides used in the cytopathology laboratory.

Notably, the same data acquisition and screening protocol can be applied for identification of HPV infection, as the technique is based on biochemical signatures, and thus, with appropriately trained spectral databases and data mining protocols, the spectral profiling could provide an integrated analysis of health status and risk of developing HSIL or cervical cancer, combining the advantages of the currently employed cytological and HPV screening standards, with higher sensitivity, specificity and throughput.

Similar potential advantages of Raman spectroscopic approaches for histopathology can be identified, although it is recognised that current mapping/imaging times of large areas of tissue followed by current pre- and post- data processing protocols need to be improved [52]. Although significant progress has been made, there is much to be done in terms of standardising procedures and protocols. The demands on the ability to rapidly scan large areas of tissue probably currently favour the use of FTIR rather than Raman spectroscopy for such applications. In terms of tissue processing protocols, there remains much debate, although consistency with current clinical practice probably favours the use of FFPP tissue samples. Notably, analyses of archived tissue libraries may add much to understanding disease progression and patient prognosis. It has been demonstrated that it is not necessary to remove the paraffin to obtain usable spectral information [53]. Leaving the paraffin in place reduces scattering artefacts and effects of further variable removal of aromatic solvent soluble components. However, it may be argued that greater consistency of spectral information is achieved when sections are deparaffinised. Deparaffinising also allows post- 
staining of the sections, although it has been demonstrated that the efficiency of the deparaffinisation process can depend on the tissue pathology [23].

In vivo applications are reliant on the further development of spectroscopic probes, which have already been demonstrated for cervical applications [44-50]. Raman spectroscopy could be a potential candidate for an adjunct tool for 'screen and treat' approaches for low resource countries. Patients are screened by visual inspection during colposcopy and treated immediately by cryotherapy if required. Raman spectroscopy could be used to improve the poor sensitivity of colposcopy in identifying cervical cancer and pre-cancerous lesions.

However, much work still remains before these techniques could be translated into standard clinical practice. Many studies have used relatively small sample sizes and as such may be biased. Validation in large multi centre studies is needed using real world cytopathology and histopathology samples from screening programmes and colposcopy clinics. Large scale clinical trials are needed to obtain the large volumes of data necessary for the development of robust classification algorithms.

If spectroscopy can be shown to be as good as, or better than, the gold standards in current use, then there is great potential for these techniques to be used as an alternative or an adjunct to the current methods. The advantages would be higher accuracy, higher throughput and reduced workload for the cytologist/pathologist and higher accuracy and chance of earlier detection for the patient. It is important, however, to establish standard operating procedures, through networks such as as the UK EPSRC Network CLIRSPEC (www.clirspec.org) and the EU COST Action Raman4Clinics (http://www.cost.eu/domains_actions/bmbs/Actions/BM1401), to engage spectroscopic instrument and medical device industries to optimise data collection efficiencies, as well as to actively engage the medical and clinical communities to encourage uptake and translation of the technologies. 


\section{Acknowledgments}

The authors acknowledge funding from Enterprise Ireland co-funded by the European Regional Development Fund (ERDF) and Ireland's EU Structural Funds Programme 2007-2013, CF2011 1045, the Health Research Board Collaborative Applied Research Grant, CARG2012/29, and Dublin Institute of Technology Fiosraigh Research Excellence Award. 


\section{References}

1. Ferlay, J.; Soerjomataram, I.; Ervik, M.; Dikshit, R.; Eser, S.; Mathers, C.; Rebelo, M.; Parkin, D.M.; Forman, D.; Bray; F. (2012) GLOBOCAN, v1.0, Cancer Incidence and Mortality Worldwide: IARC CancerBase No. 11, 2013. International Agency for Research on Cancer

2. Walboomers, J.M.; Jacobs, M.V.; Manos, M.M.; Bosch, F.X.; Kummer, J.A.; Shah, K.V.; Snijders, P.J.; Peto, J.; Meijer, C.J.; Munoz, N. (1999) Human papillomavirus is a necessary cause of invasive cervical cancer worldwide. J. Pathol. 189: 12-19

3. Franco E.L., Schlecht N.F., Saslow D. (2003) The epidemiology of cervical cancer. Cancer J, 9:348-59

4. Koss L.G., Melamed M.R. (2006) Koss' Diagnostic Cytology and Its Histopathologic Bases. Fifth Edit. Lippincott Williams \& Wilkins, Philadelphia.

5. Kurman R.J., Solomon D. (1994). The Bethesda System for Reporting Cervical/Vaginal Cytologic Diagnoses: Definitions, Criteria and Explanatory Notes for Terminology and Specimen Adequacy. Springer Verlag, New York.

6. Herbert A., Bergeron C., Wiener H., Schenck U., Klinkhamer P., Bulten J. et al. (2007) European guidelines for quality assurance in cervical cancer screening: recommendations for cervical cytology terminology. Cytopathology 18:213-219

7. Kitchener H.C.; Blanks R.; Cubie H.; Desai M.; Dunn G.; Legood R.; Gray A.; Sadique Z.; Moss S. (2011) MAVARIC Trial Study Group. MAVARIC - A comparison of automation-assisted and manual cervical screening: A randomised controlled trial. Health Technol. Assess., 15:1-170.

8. Schiffman M.; Wentzensen N.; Wacholder S.; Kinney W.; Gage J.C.; Castle P.E. (2011) Human papillomavirus testing in the prevention of cervical cancer. J. Natl. Cancer Inst. 103: 368-383.

9. Ronco G., Giorgi-Rossi P., Carozzi F., Confortini M., Dalla Palma P., Del Mistro A. et al. (2010) Efficacy of human papillomavirus testing for the detection of invasive cervical cancers and cervical intraepithelial neoplasia: a randomised controlled trial. Lancet Oncol., 11:249-257.

10. Cuzick J., Cadman L., Mesher D., Austin J., Ashdown-Barr L., Ho L. et al. (2013) Comparing the performance of six human papillomavirus tests in a screening population. Br J Cancer 108:908-13.

11. Castle P.E., de Sanjosé S., Qiao Y.L., Belinson J.L., Lazcano-Ponce E., Kinney W. (2012) Introduction of human papillomavirus DNA screening in the world: 15 years of experience. Vaccine. 20, 30 Suppl 5:F117-22

12. Dalla Palma P., Giorgi Rossi P., Collina G., Buccoliero A.M., Ghiringhello B., Lestani M. et al. (2008) The risk of false-positive histology according to the reason for colposcopy referral in cervical cancer screening: a blind revision of all histologic lesions found in the NTCC trial. Am J Clin Pathol. 129:75-80.

13. Stoler M.H., Schiffman M. (2001) Interobserver reproducibility of cervical cytologic and histologic interpretations: realistic estimates from the ASCUS-LSIL Triage Study. JAMA 285:1500-1505.

14. Parker M.F., Zahn C.M., Vogel K.M., Olsen C.H., Miyazawa K., O'Connor D.M. (2002 ) Discrepancy in the interpretation of cervical histology by gynecologic pathologists. Obstet Gynecol. 100:277-80.

15. Grenko RT, Abendroth CS, Frauenhoffer EE, Ruggiero FM, Zaino RJ. (2000) Variance in the interpretation of cervical biopsy specimens obtained for atypical squamous cells of undetermined significance. Am J Clin Pathol. 114:735-40.

16. Diem, M. (1993), Introduction to Modern Vibrational Spectroscopy; Wiley, New York 
17. Diem, M.; Mazur, A.; Lenau, K.; Schubert, J.; Bird, B.; Miljkovic, M.; Krafft, C.; Popp, J. (2013), Molecular pathology via IR and Raman spectral imaging. J. Biophotonics, 6: 855-886.

18. Ellis, D.I.; Cowcher, D.P.; Ashton, L.; O'Hagan, S.; Goodacre, R. Illuminating disease and enlightening biomedicine: Raman spectroscopy as a diagnostic tool. Analyst 2013, 138, 3871-3884.

19. Kendall, C.; Isabelle, M.; Bazant-Hegemark, F.; Hutchings, J.; Orr, L.; Babrah, J.; Baker, R.; Stone, N. (2009) Vibrational spectroscopy: A clinical tool for cancer diagnostics. Analyst, 134:1029-1045.

20. Nijssen, A.; Koljenovic, S.; Bakker Schut, T.C.; Caspers, P.J.; Puppels, G.J. (2009) Towards oncological application of Raman spectroscopy. J. Biophotonics, 2:29-36.

21. Movasaghi, Z.; Rehman, S.; Rehman, I.U. (2007) Raman Spectroscopy of Biological Tissues. Appl. Spectrosc. Rev., 42, 493-541.

22. Rashid N. (2013), Raman microspectroscopy for the characterization of cervical cancer, PhD thesis, Dublin Institute of Technology

23. Fullwood L.M., Griffiths D., Ashton K., Dawson T., Lea R.W., Davis C., Bonnier F., Byrne H.J., Baker M.J. (2014) Effect of substrate choice and tissue type on tissue preparation for spectral histopathology by Raman microspectroscopy. Analyst 139:446-54.

24. Kerr L.T., Byrne H.J., Hennelly B.M. (2015), Optimal choice of sample substrate and laser wavelength for Raman spectroscopic analysis of biological specimens, Anal Methods (accepted)

25. Fung Kee Fung, M.; Senterman, M.; Eid, P.; Faught, W.; Mikhael, N.Z.; Wong, P.T. (1997) Comparison of Fourier-transform infrared spectroscopic screening of exfoliated cervical cells with standard Papanicolaou screening. Gynecol. Oncol. 66: 10-15.

26. Neviliappan, S.; Fang Kan, L.; Tiang Lee Walter, T.; Arulkumaran, S.; Wong, P.T.T. (2002) Infrared spectral features of exfoliated cervical cells, cervical adenocarcinoma tissue, and an adenocarcinoma cell line (SiSo). Gynecol. Oncol. 85: 170-174.

27. Wong, P.T.; Wong, R.K.; Caputo, T.A.; Godwin, T.A.; Rigas, B. (1991) Infrared spectroscopy of exfoliated human cervical cells: Evidence of extensive structural changes during carcinogenesis. Proc. Natl. Acad. Sci. USA 1991, 88, 10988-10992.

28. Wong, P.T.T.; Senterman, M.K.; Jackli, P.; Wong, R.K.; Salib, S.; Campbell, C.E.; Feigel, R.; Faught, W.; Fung Kee Fung, M. (2002) Detailed account of confounding factors in interpretation of FTIR spectra of exfoliated cervical cells. Biopolymers, 67: 376-386.

29. Chiriboga, L.; Xie, P.; Vigorita, V.; Zarou, D.; Zakim, D.; Diem, M. (1998,) Infrared spectroscopy of human tissue. II. A comparative study of spectra of biopsies of cervical squamous epithelium and of exfoliated cervical cells. Biospectroscopy 4: 55-59.

30. Cohenford, M.A.; Godwin, T.A.; Cahn, F.; Bhandare, P.; Caputo, T.A.; Rigas, B. (1997) Infrared spectroscopy of normal and abnormal cervical smears: Evaluation by principal component analysis. Gynecol. Oncol., 66: 59-65.

31. Diem, M.; Chiriboga, L.; Lasch, P.; Pacifico, A. (2002) IR spectra and IR spectral maps of individual normal and cancerous cells. Biopolymers 67: 349-353.

32. Romeo, M.J.; Quinn, M.A.; Burden, F.R.; McNaughton, D. (2002) Influence of benign cellular changes in diagnosis of cervical cancer using IR microspectroscopy. Biopolymers 67: 362-366. 
33. Wood, B.R.; Quinn, M.A.; Tait, B.; Ashdown, M.; Hislop, T.; Romeo, M.; McNaughton, D. (1998) FTIR microspectroscopic study of cell types and potential confounding variables in screening for cervical malignancies. Biospectroscopy 4: 75-91.

34. Rubina, S.; Amita, M.; Kedar, K.D.; Bharat, R.; Krishna, C.M. (2013) Raman spectroscopic study on classification of cervical cell specimens. Vib. Spectrosc. 68: 115-121.

35. Bonnier, F.; Traynor, D.; Kearney, P.; Clarke, C.; Knief, P.; Martin, C.; O’Leary, J.J.; Byrne, H.J.; Lyng, F. (2014) Processing ThinPrep cervical cytological samples for Raman spectroscopic analysis. Anal. Methods 6: 7831-7841.

36. Jess P.R.T., Simth D.D.W., Mazilu M., Dholakia K., Riches A.C., Herrington C.S. (2007) Early detection of cervical neoplasia by Raman spectroscopy. International Journal of Cancer 121:2723-2728.

37. Ostroswka K.M., Malkin A., Meade A., O’Leary J., Martin C., Spillane C., Byrne H.J., Lyng F.M. (2010) Investigation of the influence of high-risk human papillomavirus on the biochemical composition of cervical cancer cells using vibrational spectroscopy. Analyst 135:3087-3093

38. Vargis, E.; Tang, Y.-W.; Khabele, D.; Mahadevan-Jansen, A. (2012) Near-infrared Raman Microspectroscopy Detects High-risk Human Papillomaviruses. Transl. Oncol. 5: 172-179.

39. Krishna C.M., Sockalingum G.D., Vadhiraja B.M., Maheedhar K., Rao A.C.K., Rao L., Venteo L., Plutot M., Fernandes D.J., Vidyasagar M.S., Kartha B.V.B., Manfait M. (2006) Vibrational Spectroscopy Studies of Formalin-Fixed Cervix Tissues. Biopolymers 85:214-221.

40. Lyng F.M., Faolain E.O., Conroy J., Meade A.D., Knief P., Duffy B., Hunter M.B., Byrne J.M., Kelehan P., Byrne H.J. (2007) Vibrational spectroscopy for cervical cancer pathology, from biochemical analysis to diagnostic tool. Experimental and Molecular Pathology 82:121-129.

41. Kamemoto L.E., MisRa A.K., Sharma S.K., Goodman M.T., Luk H., Dykes A.C., Acosta T. (2010) NearInfrared Micro-Raman Spectroscopy for in Vitro Detection of Cervical Cancer. Applied Spectroscopy $64: 255-261$.

42. Tan K.M., Herrington C.S., Brown C.T. (2011) Discrimination of normal from pre-malignant cervical tissue by Raman mapping of de-paraffinized histological tissue sections. J Biophotonics 4: 40-8

43. Rashid N., Nawaz H., Poon K.W., Bonnier F., Bakhiet S., Martin C., O'Leary J.J., Byrne H.J., Lyng F.M. (2014) Raman microspectroscopy for the early detection of pre-malignant changes in cervical tissue. Exp Mol Pathol. 97:554-64.

44. Mahadevan-Jasen A., Mitchel M.F., Ramanujam N., Utzinger U., Richards-Kortum R. (1998) Development of a Fiber Optic Probe to Measure NIR Raman Spectra of Cervical Tissue In Vivo. Photochemistry and Photobiology. 68:427-431.

45. Utzinger U., Heintzelman D.L., Mahadevan-Jasen A., Malpica A., Folen M., Richards-Kortum R. (2001) Near-Infrared Raman Spectroscopy for in Vivo Detection of Cervical Precancers. Applied Spectroscopy. 55:959-995.

46. Kanter E.M., Majumder S., Kanter G.J., Woeste E., Mahadevan-Jasen A. (2009) Effect of hormonal variation on Raman spectra for cervical disease detection. American Journal of Obstetrics \& Gynecology. 200:512.e1-5.

47. Vargis E., Kanter E.M., Majumder S., Keller M.D., Beaven R.B., Rao G.G., Mahadevan-Jasen A. (2011) Effect of normal variations on disease classification of Raman spectra from cervical tissue. Analyst. 136:2981-2987. 
48. Vargis E., Byrd T., Logan Q., Khabele D., Mahadevan-Jansen A. (2011) Sensitivity of Raman spectroscopy to normal patient variability. Journal of Biomedical Optics 16:117004.

49. Mo J., Zheng W., Low J.J.H., Ng J., Ilancheran A., Huang Z. (2009) High Wavenumber Raman Spectroscopy for in Vivo Detection of Cervical Dysplasia. Analytical Chemistry. 81:8908-8915.

50. Duraipandian S., Zheng W., Ng J., Low J.J.H., Ilancheran A. (2012) Simultaneous Fingerprint and HighWavenumber Confocal Raman Spectroscopy Enhances Early Detection of Cervical Precancer In Vivo. Analytical Chemistry. 84:5913-5919.

51. Byrne H.J., Baranska M., Puppels G.J., Stone N., Wood B., Gough K.M., Lasch P., Heraud P., Sulé-Suso J., Sockalingum G.D. (2015), Spectropathology for the Next Generation: Quo Vadis? Analyst, 140:2066 2073

52. Bassan P., Sachdeva A., Shanks J., Brown M.D., Clarke N.W. and Gardner P. (2013), Whole organ crosssection chemical imaging using label-free mega-mosaic FTIR microscopy Analyst, , 138: 7066-7069.

53. Tfayli A., Gobinet C., Vrabie V., Huez R., Manfait M., Piot O. (2009) Digital dewaxing of Raman signals: discrimination between nevi and melanoma spectra obtained from paraffin-embedded skin biopsies. Appl Spectrosc. 63:564-70. 


\section{Figure Legends}

Figure 1 Pap stained negative Thinprep slide showing parabasal (black arrowheads), intermediate (solid arrows) and superficial (dashed arrows) cells and white blood cells (red arrowheads)

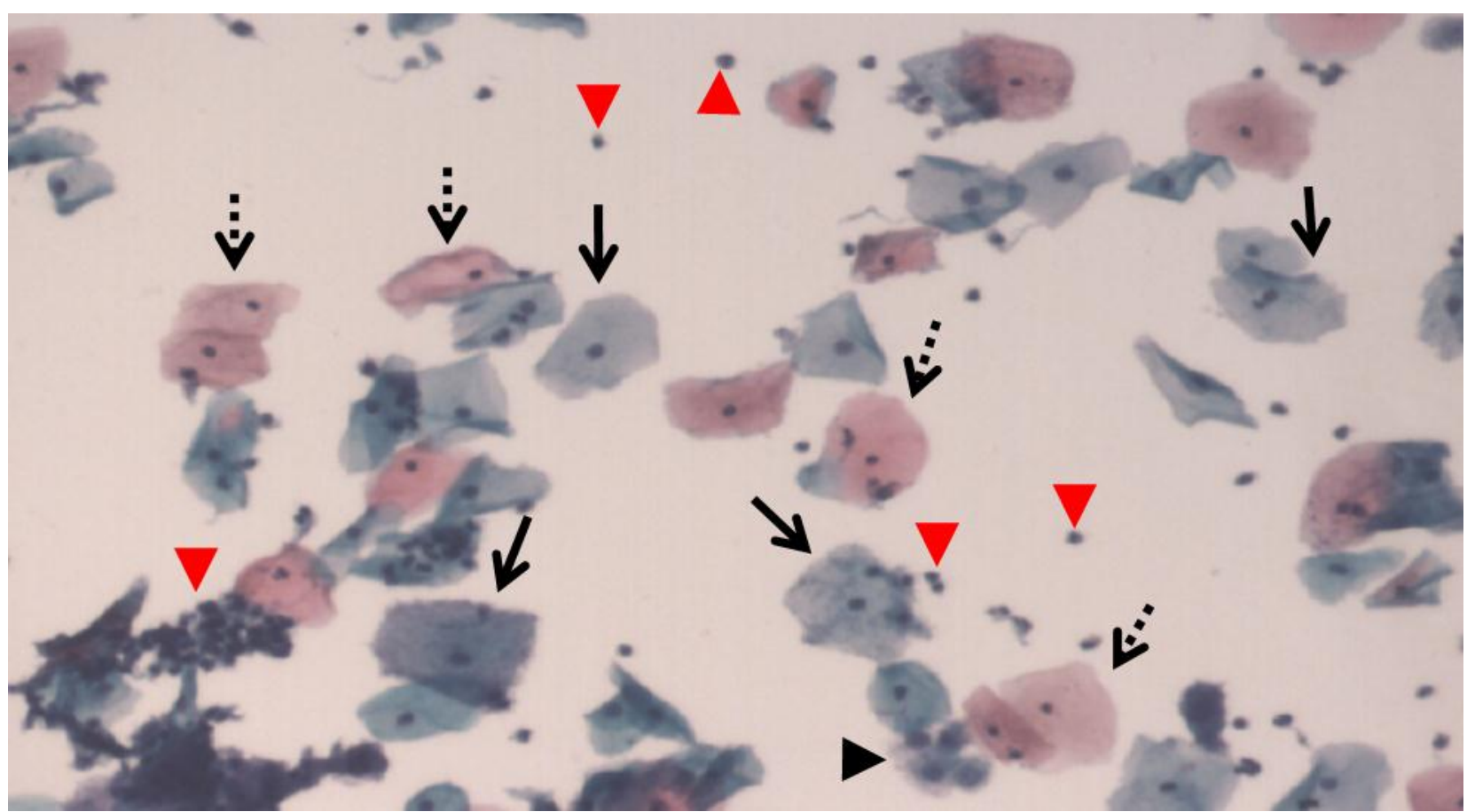


parabasal (red arrow), intermediate / superficial layers (green arrow)

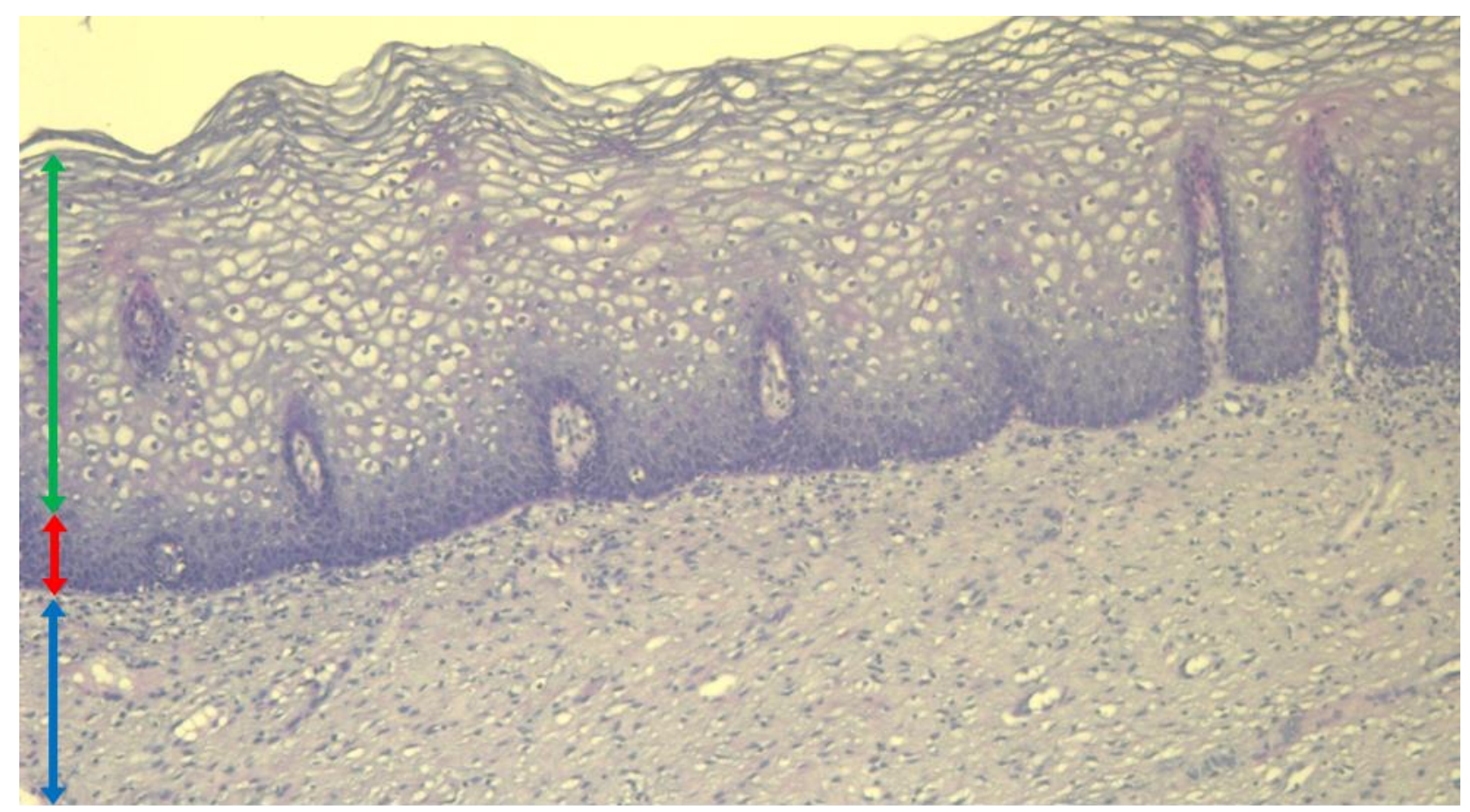


Figure 3 Raman spectrum of cervical cells showing fingerprint and high wavenumber regions

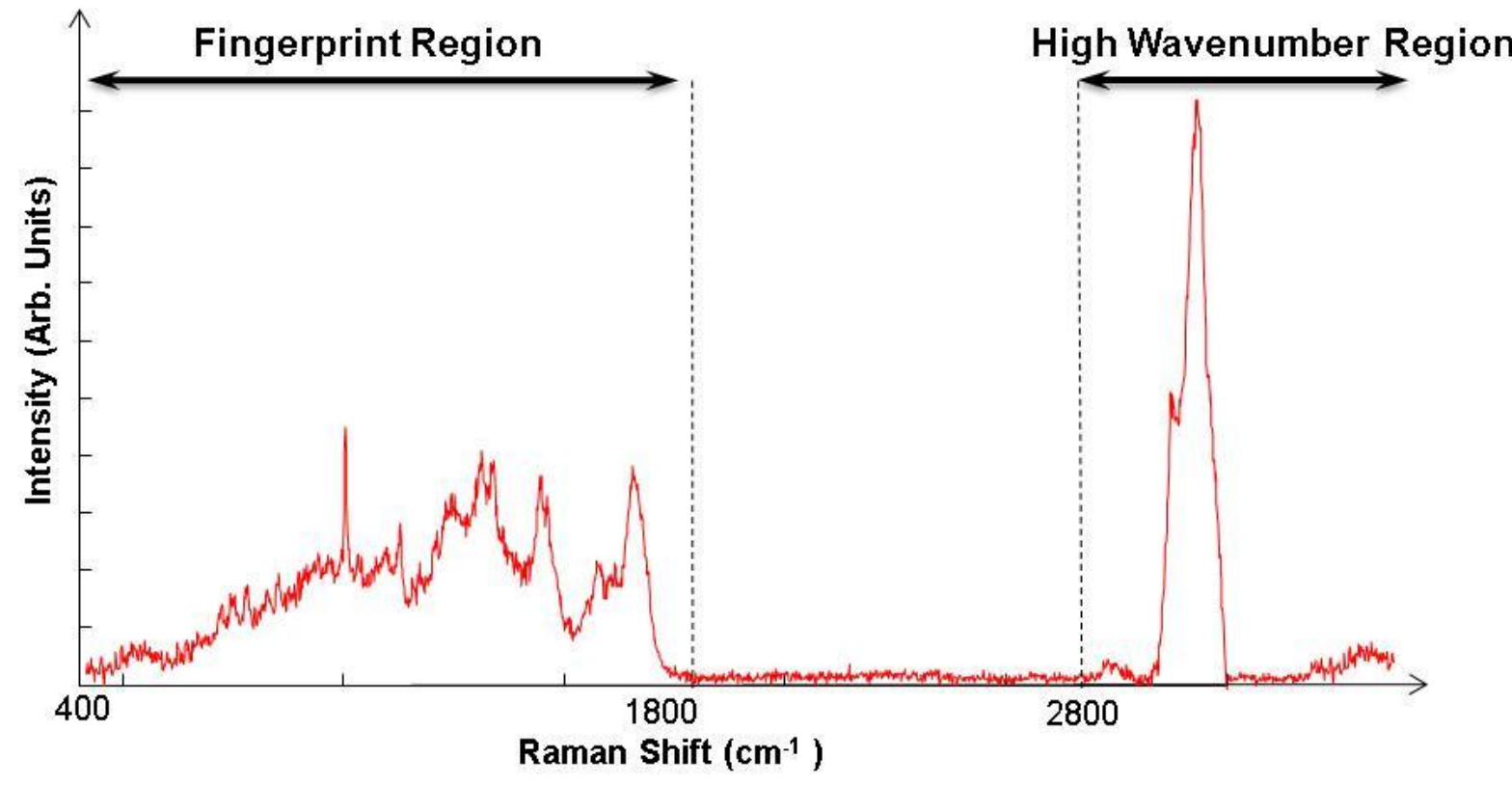


Figure 4

(I) Pap stained negative Thinprep slide showing parabasal (black arrowheads), intermediate

(solid arrows) and superficial (dashed arrows) cells and white blood cells (red arrowheads) and (II) mean Raman spectra from parabasal (light blue), intermediate (blue) and superficial (red) cells and white blood cells (bottom)

I)

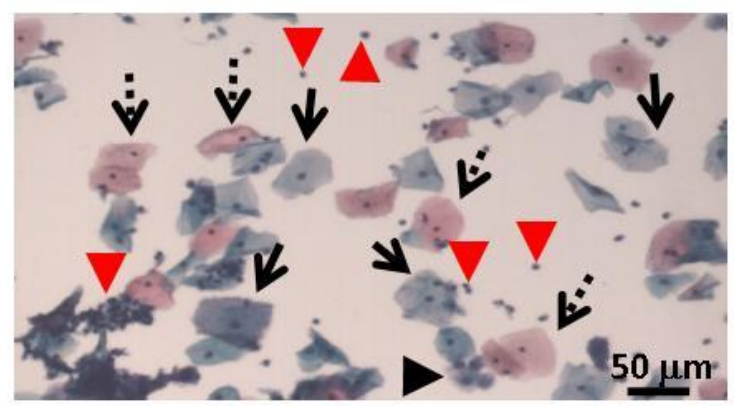

II)

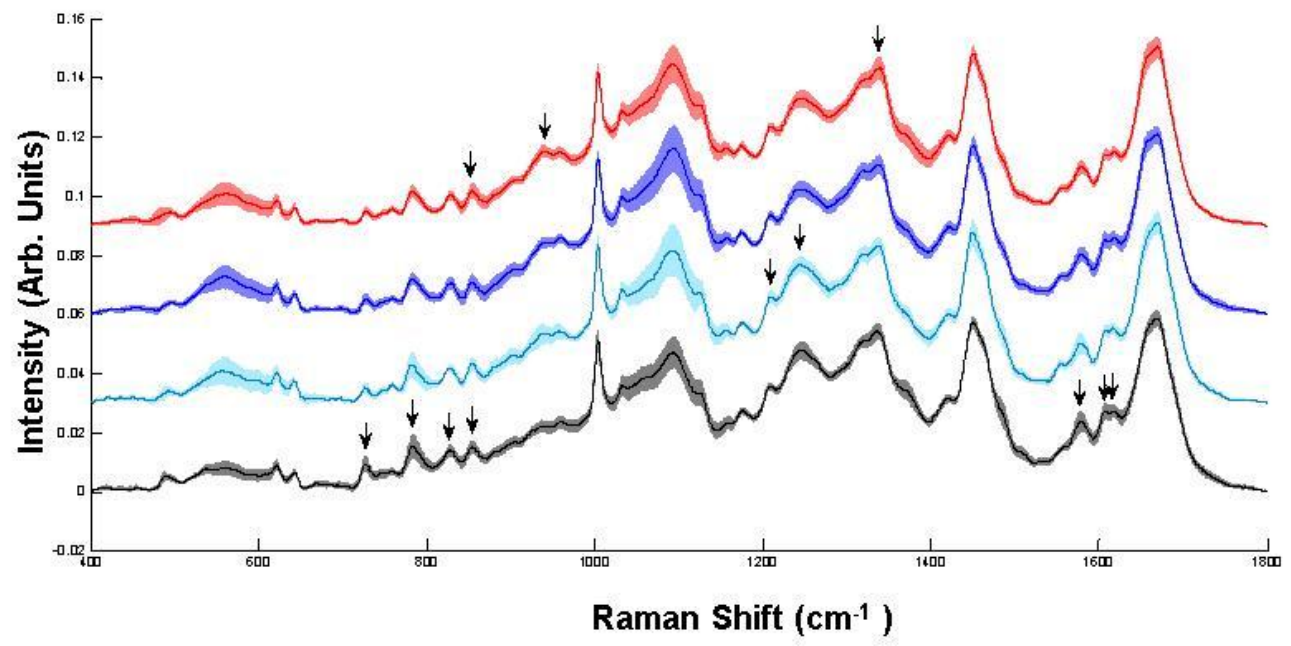


Figure 5 (I) Unstained and (II) H\&E stained normal cervical tissue showing stromal, basal, intermediate / superficial layers, (III) Raman spectral map showing stromal (blue), basal (red) and intermediate / superficial (green) layers and (IV) mean Raman spectra from each representative layer

I)

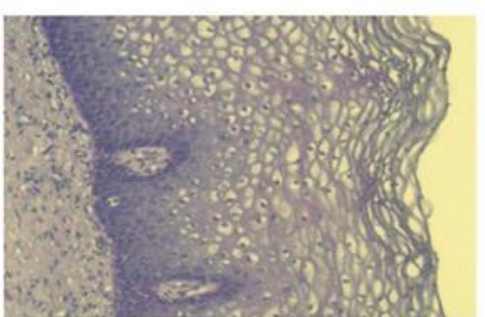

III)

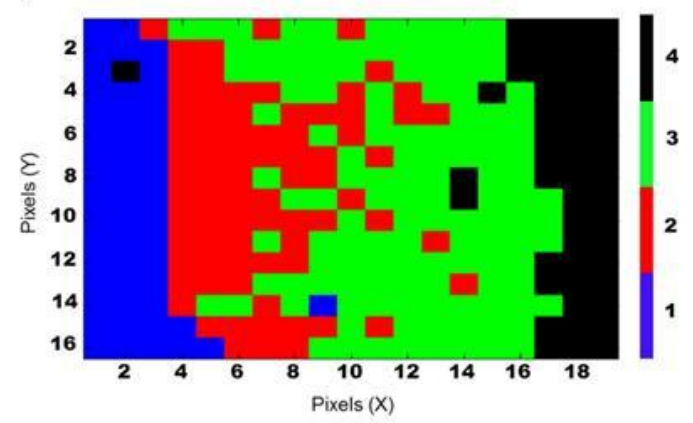

II)

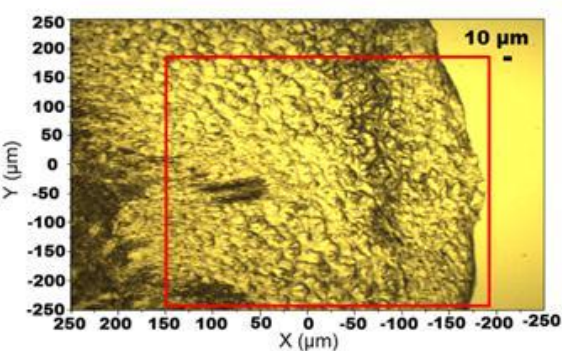

IV)

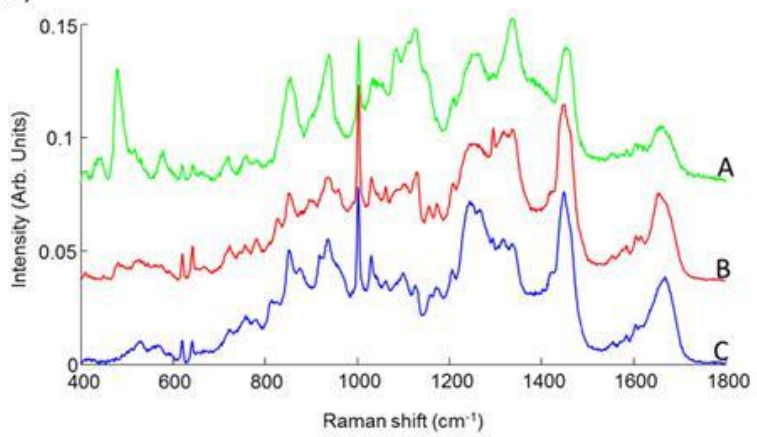


Table 1 Tentative peak assignments [15] for Raman spectrum shown in Figure 3.

\begin{tabular}{|c|c|}
\hline Wavenumber $\left(\mathrm{cm}^{-1}\right)$ & Raman Peak Assignments \\
\hline 621 & $\mathrm{C}-\mathrm{C}$ twisting mode of Phenylalanine (proteins) \\
\hline 642 & $\mathrm{C}-\mathrm{C}$ twisting mode of Tyrosine and Phenylalanine \\
\hline 670 & Thymine, Guanine (DNA/RNA) \\
\hline 720 & C-N stretching in Adenine and lipids \\
\hline 750 & symmetric breathing of Tryptophan (protein) \\
\hline 782 & Uracil, Thymine, Cytosine (ring breathing modes in the DNA/RNA) \\
\hline 827 & $\mathrm{PO}_{2}$ stretching in DNA, Tyrosine \\
\hline 854 & Ring breathing in Tyrosine and Proline (proteins) \\
\hline 935 & $\mathrm{C}-\mathrm{C}$ stretching mode of Proline and Valine \\
\hline 1003 & $\mathrm{C}-\mathrm{C}$ aromatic ring stretching in Phenylalanine \\
\hline 1030 & $\mathrm{C}-\mathrm{H}$ bending mode in Phenylalanine, $\mathrm{C}-\mathrm{N}$ stretching in proteins \\
\hline 1080 & $\mathrm{PO}_{2}$ symmetric stretching (DNA/RNA) \\
\hline 1085 & C-O stretching \\
\hline 1130 & $\mathrm{C}-\mathrm{N}$ stretching in proteins; $\mathrm{C}-\mathrm{O}$ stretching in carbohydrates \\
\hline 1155 & $\mathrm{C}-\mathrm{C}$ and $\mathrm{C}-\mathrm{N}$ stretching of proteins/lipids \\
\hline 1175 & $\begin{array}{l}\text { C-H in plane bending mode of Tyrosine and Phenylalanine; Cytosine, } \\
\text { Guanine }\end{array}$ \\
\hline 1208 & C- $\mathrm{C}_{6} \mathrm{H}_{5}$ stretching mode in Tryptophan, Phenylalanine; \\
\hline $1220-1280$ & $\begin{array}{l}\text { Amide III (C-N stretching, } \mathrm{N}-\mathrm{H} \text { bending, proteins), } \mathrm{PO}_{2} \text { asymmetric stretching } \\
\text { (DNA/RNA) }\end{array}$ \\
\hline 1311 & $\mathrm{CH}_{3} / \mathrm{CH}_{2}$ twisting mode of collagen and lipid \\
\hline 1340 & Guanine (DNA/RNA), $\mathrm{CH}$ def. in proteins and carbohydrates \\
\hline $1430-1460$ & $\mathrm{CH}\left(\mathrm{CH}_{2}\right)$ bending mode in proteins and lipids \\
\hline 1485 & $\begin{array}{l}\text { Amide II (N-H bending, C-N stretching, proteins); Adenine, Guanine } \\
\text { (DNA/RNA) }\end{array}$ \\
\hline 1580 & Adenine, Guanine (DNA/RNA); $\mathrm{C}=\mathrm{C}$ bending mode of Phenylalanine \\
\hline 1615 & $\mathrm{C}=\mathrm{C}$ Phenylalanine, Tyrosine and Tryptophan \\
\hline $1620-1700$ & Amide $\mathrm{I}(\mathrm{C}=\mathrm{O}$ stretching, $\mathrm{C}-\mathrm{N}$ stretching and $\mathrm{N}-\mathrm{H}$ bending, proteins) \\
\hline
\end{tabular}


